\title{
Jovem e consumo midiático: mapeando práticas juvenis das regiões Sul e Sudeste
}

\author{
Daniela Schmitz \\ Doutora em Comunicação e Informação \\ pela Universidade Federal do Rio \\ Grande do Sul (UFRGS). Pós-doutoranda \\ do Programa de Pós-Graduação \\ em Comunicação e Informação da \\ Universidade Federal do Rio Grande \\ do Sul (PPGCOM/UFRGS), bolsista de \\ Pós-Doutorado Júnior do Conselho \\ Nacional de Desenvolvimento Científico \\ e Tecnológico (CNPq). \\ E-mail: danischmitz@ymail.com
}

\section{Alexia Oliveira Barbieri \\ Mestranda do Programa de Pós-Graduação em Antropologia Social e bacharel em Ciências Sociais pela UFRGS. Mestranda do Programa de Pós-Graduação em Antropologia Social da Universidade Federal do Rio Grande do Sul (PPGAS/UFRGS), bolsista CNPq. \\ E-mail: alexiabarbieri3@gmail.com}

Resumo: Este artigo apresenta uma análise comparativa de práticas de consumo midiático entre jovens das regiões Sul e Sudeste do Brasil. Os dados são oriundos de uma pesquisa nacional desenvolvida entre 2012 e 2015 pela Rede Brasil Conectado, cujo objetivo foi mapear práticas juvenis no atual contexto de convergência tecnológica, cultural e midiática. Discute-se aqui parte de um questionário on-line respondido nacionalmente por mais de nove mil jovens. $\mathrm{Na}$ interpretação dos dados, utilizou-se software de análise qualitativa, o NVivo, que potencializou e acelerou o processo. Sobre os resultados, percebeu-se que o perfil dos jovens dessas regiões é bastante similar e que seu consumo midiático, apesar de se assemelhar por um lado, apresenta nuances destacadas nas formas e intensidades desses consumos, dados que serão explorados ao longo do artigo.

Palavras-chave: Consumo Midiático; Convergência; Juventude.

\section{Media consumption and youth: mapping youth practices of south and southeast} Brazil

Abstract: In this paper we present a comparative analysis of media practices and consumption of south and southeast Brazilian youth. Data are derived from a national comparative research developed between 2012 and 2015 and conducted by Rede Brasil Conectado. We intend to map youth media consumption in the current context of technological, cultural and media convergence. The results covered here are part of an online survey answered by more than nine thousand young people. When analyzing data, we used a qualitative analysis software, Nvivo, that expanded and accelerated the process. We concluded that young people's profiles in these regions are similar, on the other hand, their media consumption - although being alike - presents important differences on forms and intensity of these consumptions, which we are going to investigate in this study.

Keywords: Media Consumption; Convergence; Youth. 


\section{Introdução}

${ }^{1}$ Uma versão preliminar deste texto foi apresentada na III Jornada de Pesquisadores da Recepção, ocorrido em julho de 2016, na Universidade do Vale do Rio dos Sinos.

${ }^{2}$ A rede é coordenada pela Dra. Nilda Jacks e conta com pesquisadores nos 26 estados brasileiros, mais o Distrito Federal. Mais informações sobre a rede disponíveis em: <https://goo.gl/dq×2aG>.

${ }^{3} \mathrm{Em}$ ambos procedimentos buscou-se trabalhar com cinco garotas e cinco garotos.
${ }^{4}$ A saber: término da escola, início de atividade profissional, relação conjugal estável, saída da casa paterna/materna e experiência com a maternidade/ paternidade.
Este artigo apresenta e discute dados produzidos na pesquisa nacional "Jovem e consumo midiático em tempos de convergência", ${ }^{1}$ da Rede Brasil Conectado. ${ }^{2} \mathrm{~A}$ investigação foi desenvolvida entre os anos de 2012 e 2015, e valeu-se de grande esforço integrado de pesquisa a fim de mapear o consumo midiático juvenil brasileiro no atual contexto de convergência tecnológica, cultural e midiática.

De forma resumida, o trabalho de campo se deu em três etapas: a primeira buscou dados contextuais (históricos, econômicos, demográficos, culturais, midiáticos etc.) dos estados e suas respectivas capitais, incluindo o Distrito Federal. A segunda fase esteve focada nos jovens das capitais e regiões metropolitanas e combinou um estudo-piloto (aplicação presencial de questionário com 108 perguntas para dez jovens de cada estado), com pesquisa exploratória (observação de uma semana de perfis no Facebook de outros dez jovens de cada estado). ${ }^{3}$ Os procedimentos visavam mapear o consumo cultural e midiático de universitários entre 18 e 24 anos, de classes populares. Já a terceira etapa consistiu na aplicação de questionário on-line, orientado pelos dados construídos nas etapas anteriores, buscando aprofundar questões e insights, bem como explorar importantes eixos da pesquisa. Esse questionário era composto por 31 perguntas e foi respondido por 9.072 jovens entre 18 e 24 anos de todo o Brasil.

O foco deste artigo recai especificamente neste último instrumento utilizado na investigação, apresentando alguns dados e análises comparativas entre práticas de jovens da região Sul e Sudeste do país, economicamente mais desenvolvidas e que contavam com número de respondentes muito próximo, o que amplia possibilidades de comparação entre os dois grupos.

Antes de apresentar os dados, expõe-se parte do panorama teórico que guiou a investigação, para focar nas estratégicas metodológicas empregadas, especialmente na utilização de um software de análise qualitativa, o NVivo, que ampliou e potencializou as possibilidades de análise do material empírico.

\section{Juventude e consumo midiático}

Juventude é conceito plural em que aspectos sociais e culturais instauram diversidade e impossibilitam uniformidade de vivências (FEIXA, 1999; 2004; GROPPO, 2000; 2015; MARGULIS; URRESTI, 2008). Não há consenso entre pensadores sobre o que caracteriza tal período, mas toma-se em conta a posição dos autores supracitados para entender que, no país, coexistem distintas formas de ser e de vivenciar o período que se interpõem entre infância e vida adulta. Groppo (2015: 569), em revisão das principais concepções sociológicas da juventude na atualidade, argumenta que "deixa de ser (apenas) uma categoria etária e se torna uma 'representação social', um 'modo de ser', um 'modo de existência' ou uma 'forma signo': a saber, a 'forma-juventude'". Diante da dimensão que o "ser jovem" adquire, o autor aponta para dois movimentos: alargamento do período juvenil e implosão dos tradicionais marcadores que colocavam fim ao período. ${ }^{4}$

Assim, para além da situação social e cultural historicamente constituída, as épocas, o gênero e as diferentes gerações interferem, edificam e possibilitam diferentes formas de ser jovem. Margulis e Urresti (2008) argumentam ainda que a classe marca a forma e o tempo em que se estende a juventude, pois nos setores sociais de menor poder aquisitivo, habitualmente, jovens aceleram sua entrada no mercado de trabalho, antecipam a saída da casa dos pais e vivenciam precocemente outros ritos que acompanham a transição, como manutenção de um relacionamento estável e a chegada de filhos.

Portanto, destaca-se o fato de que é uma construção histórica e social que ultrapassa a condição imposta pela idade, diferentemente do que foi postulado por 
${ }^{5}$ Este intervalo é um recorte dentro do critério de faixa etária do Estatuto da Juventude que define a idade entre 15 e 29 anos para delimitar o período juvenil (ESTATUTO..., 2014). Contudo, está dentro dos critérios estabelecidos pelo IBGE.
Bourdieu (1990) em artigo clássico sobre o tema. Para o autor, a juventude como categoria está inscrita em um limite etário que só faz sentido na contraposição: juventude e velhice são construções sociais oriundas justamente da luta entre os dois. Mesmo admitindo ser uma construção cultural, para Margulis e Urresti (2008), a discussão de Bourdieu desvincula condicionantes históricos e materiais que ajudam a construir a noção de juventude, como já apontado.

Aqui parte-se do princípio de que a juventude pode ser tomada como categoria social (GROPPO, 2000) e, assim, ultrapassa a delimitação marcada apenas pela faixa etária, sendo também representação simbólica e situação social. Porém, na argumentação do mesmo autor, não é possível desconsiderar por completo o critério idade, uma vez que acompanha - expresso ou subjacente - as definições sobre o período juvenil. E é por isso que, na construção do grupo pesquisado, acabou-se por definir um critério de idade (18 a 24 anos), ${ }^{5}$ embora se entenda que a juventude é muito mais do que um intervalo etário que antecede o que se convencionou chamar de fase adulta.

Ainda no panorama teórico edificado, o entendimento que se tem do consumo midiático toma por base a argumentação de García Canclini (2006) e sua proposta de análise sociocultural do consumo. De modo sintético, o autor coloca sua abordagem do consumo como sendo "um conjunto de processos socioculturais em que se realizam a apropriação e os usos dos produtos" (Ibid.: 80). E, para o autor, todo consumo é cultural, pois o ato de adquirir qualquer bem é muito mais amplo do que a ação de posse. Independentemente do que se consuma, o processo inclui distinção simbólica, assim como integra e comunica, objetiva desejos e ritualiza a satisfação. Sendo assim, o próprio autor lança a questão do porquê da necessidade de se distinguir entre consumo e consumo cultural - empregado no caso de determinados bens ou atividades, principalmente nas artes e nas ciências. Sua argumentação para tal separação vai no seguinte sentido: a independência e autonomia dos campos artísticos e intelectuais na modernidade acabou criando circuitos independentes para produção e circulação da arte, literatura e conhecimento. E, para o autor:

Os produtos denominados culturais têm valor de uso e troca, contribuem para a reprodução da sociedade e às vezes para a expansão de capital, porém neles os valores simbólicos prevalecem sobre os utilitários e mercantis. (Ibid.: 88).

García Canclini não caracteriza consumo midiático como modalidade específica, pois integra-o ao consumo cultural. Contudo, destaca algumas especificidades do consumo de meios, pois produtos midiáticos possuem determinada autonomia que diz respeito à dinâmica própria de produção, estilo, circulação e consumo, além de maior implicação econômica, o que permite pensar sobre consumo midiático como vertente do consumo cultural. Esta é a perspectiva aqui adotada.

Desta forma, consumo midiático refere-se ao que a mídia oferece nos grandes meios - televisão, rádio, jornal, revista, internet etc. - e nos produtos/conteúdos veiculados por eles - novelas, filmes, notícias, informações, entretenimentos, moda, shows, publicidade, entre outros, como apontam Toaldo e Jacks (2013). É possível, portanto, entender estudos sobre consumo midiático como da ordem da relação mais ampla com os meios de comunicação, sua presença no cotidiano pauta tempos, espaços, relações, percepções e pode ou não focalizar determinado meio ou gênero midiático. $O$ que os difere da noção de recepção comumente adotada na vertente dos estudos culturais latino-americanos. Nessa tradição, a análise no mais das vezes é direcionada à produção de sentidos operada a partir desse consumo, numa mirada que se opera dentro de nível micro de análise, reconstruindo como determinada mensagem de um produto midiático é decodificada, compreendida e apropriada por um grupo de sujeitos. Por outro lado, uma perspectiva mais atual de consumo cultural/midiático, segundo García 
${ }^{6}$ Ainda sobre as distinções entre consumo midiático e recepção, indica-se os trabalhos de Toaldo e Jacks (2013) e Schmitz (2015).

\footnotetext{
${ }^{7}$ As opções de resposta eram: celular, internet, jornal impresso, jornal on-line, livros, rádio, revista impressa, revista on-line, smartphone, tablet, TV e a opção de nenhum meio.
}

${ }^{8}$ As opções de resposta eram: rádio, TV, computador, celular, tablet, jornal impresso, revista impressa, livros e sempre uso mais de um meio ao mesmo tempo.
Canclini e Rosas Mantecon (2005), deve ser tomada para além da compreensão da recepção de um produto particular, mas como conjunto de processos que condicionam e atravessam esta recepção. ${ }^{6}$

Ainda dentro do panorama de consumo midiático juvenil mapeado, toma-se como contexto os processos de convergência que, para Jenkins (2008), são um fenômeno que extrapola questões técnicas, envolvendo também a ação e as práticas de produtores e consumidores de conteúdos midiáticos. É, portanto, processo de mão dupla que ocorre tanto de "cima para baixo", no âmbito corporativo, envolvendo "materiais e serviços produzidos comercialmente, circulando por circuitos regulados e previsíveis", quanto de "baixo para cima", à medida que "consumidores estão aprendendo a utilizar as diferentes tecnologias para ter um controle mais completo sobre o fluxo da mídia e para interagir com outros consumidores" (JENKINS, 2008: 44).

Nesse cenário, a transição entre tecnologias midiáticas ou entre mídias diferentes utilizadas em rede por um ou mais usuários torna-se mais do que mudança de telas à medida que a interação do usuário com o suporte transforma também seu comportamento e sua forma de consumo. A partir da digitalização dos meios e o desenvolvimento de interfaces, a relação com as telas passa a ser cada vez mais interativa.

Esse cenário de transformações não retrata somente questões de tecnologia, uma vez que a utilização de aparelhos e seus recursos passa pela vontade e pela atividade do usuário, também é condicionado por questões de classe e competência cultural, para citar apenas duas mediações (MARTíN-BARBERO, 2003) implicadas no processo. $O$ acesso às tecnologias modifica hábitos que, por sua vez, modificam características e funcionalidade dos meios. A investigação sobre consumo midiático torna-se importante, portanto, para a compreensão das amplas transformações nas formas de consumo advindas da inserção e acesso a novas tecnologias, especialmente relativas aos jovens que estão no âmago dessa utilização.

\section{O questionário nacional e a metodologia de análise}

O questionário on-line foi o último instrumento aplicado na pesquisa "Jovem e consumo midiático em tempos de convergência", fez, portanto, parte da terceira etapa de produção de dados empíricos. Era composto de 31 questões, dentre as quais seis abertas, que estiveram on-line por sete semanas (entre agosto e outubro de 2014). Um total de 9.072 jovens de todo o país respondeu ao questionário, sendo que 6.741 (71\%) o fizeram por completo. Tratou-se, portanto, de amostragem não aleatória, por conveniência.

O questionário explorou o acesso à internet, a circulação de conteúdos neste ambiente, o uso de redes sociais e a comunicação via web, a posse e uso de dispositivos, a importância dos meios e seus usos convergentes, além de perguntas relativas ao perfil do jovem.

Aqui serão explorados dados de quatro questões especificamente, entre elas duas fechadas, seguidas de perguntas abertas que contribuíam para compreender sentidos atribuídos aos usos e práticas de consumo midiático juvenil. São: a) Quais meios de comunicação não fazem falta para você hoje? (marque até 3$) ;{ }^{7}$ b) Por que os meios marcados não fazem falta para você?; c) De todos os meios abaixo listados, marque os que você dedica atenção exclusiva, ou seja, você só presta atenção em um deles por vez (marque até 3 opções); ${ }^{8}$ d) Por que você dedica atenção exclusiva a esse(s) meio(s) quando o(s) utiliza?

As perguntas fechadas foram tratadas no software SPSS (Statistical Package for the Social Sciences), que facilitou a organização, sistematização e análise do 
${ }^{9} \mathrm{O}$ software possibilita que um conjunto de dados quantitativos possa ser explorado em correlação, regressão, comparação, análise de variância, entre outras ações que, facilitadas, possibilitam grande número de inferências (TEIXEIRA; BECKER, 2001).

${ }^{10}$ Originados nos Estados Unidos na década de 1960, esses programas tinham funções limitadas inicialmente como "recorte de fichas, codificação de textos por meio de sublinhados ou a reunião de dados em um documento mestre" (OROZCO GÓMEZ; GONZÁLEZ, 2012: 194). Em meados dos anos 1980, com avanços da informática e da tecnologia, os programas começam a se desenvolver, tornando-se cada vez mais atraentes a pesquisadores que investem em abordagens qualitativas.

${ }^{11} \mathrm{~A}$ categorização de algumas questões abertas precisou ser refeita com base na auditoria realizada.

${ }^{12} \mathrm{Em}$ função dos limites do artigo, será apresentada apenas uma nuvem de palavras e uma árvore de significados para que seja possível compreender a metodologia de análise utilizada. Os demais dados serão apenas descritos. material de cunho quantitativo. ${ }^{9}$ Aqui utilizou-se apenas o total de questionários respondidos até o final, ou seja, apenas as respostas de 6.741 jovens.

Já no caso das seis questões abertas tratadas qualitativamente, utilizou-se a totalidade das respostas de cada pergunta, o que faz com que haja número diferente de respondentes em cada. O que se percebeu na análise dos dados é que o número de jovens que abandonava o questionário sem completá-lo aumentava a cada questão aberta com que se deparavam. O que acarreta em maior número de respondentes nas questões iniciais do instrumento. Este material foi trabalhado no NVivo, software CAQDAS (Computer Assisted Qualitative Data Analysis Software), ${ }^{10}$ que permitiu organizar, explorar e interpretar a extensa base de dados qualitativa construída com o discurso juvenil sobre práticas de consumo midiático, além de relacioná-lo com as questões precedentes, de caráter fechado. Tal potencialidade está de acordo com a argumentação de Cresswell (2007) que indica que as ferramentas informacionais são mais úteis em grandes bancos de dados, como o analisado aqui, mas também podem ser bem aproveitadas em pesquisas menores.

Para o tratamento das questões abertas, inicialmente, metade das respostas dos jovens de todas as regiões foi lida de forma exploratória a fim de criar categorias indutivas que contribuíssem para a interpretação de tais questões. Definidas as categorias, parte desse material foi categorizado manualmente no NVivo (cerca de 100 respostas para cada categoria) para então empregar recurso de codificação automática (com uso de inteligência artificial) das cerca de 9.000 respostas restantes com base nos padrões das respostas manualmente codificadas. Uma amostra de, aproximadamente, $30 \%$ desse material foi auditado, exercício no qual foi possível perceber que a codificação automática com base em inteligência artificial atingiu índice de confiabilidade de cerca de $92 \%$ do total de respostas. ${ }^{11}$

Destaca-se que o cruzamento de respostas fechadas com respostas abertas, partindo das categorias indutivas identificadas foi possível porque, ao quantificar os dados das perguntas abertas com base nas categorias que emergiram da leitura exploratória, ambos os grupos de dados eram de natureza quantitativa. Com o uso do software Nvivo, além da possibilidade de utilizar inteligência artificial na categorização e cruzar questões de naturezas distintas, a ferramenta organizou e agrupou as respostas abertas dos jovens a partir de questionamento de viés quantitativo. Essa organização permitiu explorar, ainda que de forma não sistemática, as respostas a fim de ler algumas na íntegra e, assim, apropriar-se do discurso juvenil associado aos recursos analíticos a seguir apresentados.

Na sequência, foram geradas nuvens de palavras com o cruzamento dos dados das respostas fechadas e as categorias indutivas identificadas em cada questão aberta, destacando termos mais proeminentes no discurso dos jovens, conforme se verá mais à frente, na apresentação dos dados. Após análise dessa nuvem, foram eleitos alguns termos-chave para criação de árvores de significado. Esse material traz um panorama do "campo de sentidos" que envolve determinada palavra, ou seja, aponta algumas recorrências no discurso dos jovens, tendo como centro a expressão eleita. À esquerda do termo há frases e expressões que precedem tal palavra e, à direita, a fala que a sucede. ${ }^{12}$

\section{Consumo midiático entre jovens do Sul e Sudeste}

Para este artigo foram analisadas respostas a duas perguntas fechadas obtidas de jovens da região Sul (1.118) e Sudeste (1.120) que completaram as 31 questões do instrumento. Nas duas perguntas abertas que exploraram qualitativamente as opções indicadas nas questões fechadas, o total de respondentes varia de acordo com a questão, uma vez que se optou por incorporar todas as respostas obtidas na amostra construída com 9.072 jovens. Com essas decisões, buscouse ampliar as possibilidades de comparação entre os dois grupos, uma vez 
que os discursos de todos os jovens construídos nas perguntas abertas foram incorporados. A Tabela 1, a seguir, aponta a origem dos respondentes.

\begin{tabular}{|l|l|c|c|}
\hline \multirow{2}{*}{ Região } & Estado & $\begin{array}{l}\text { Total de } \\
\text { respondentes }\end{array}$ & $\begin{array}{l}\text { Total que completou o } \\
\text { questionário }\end{array}$ \\
\hline \multirow{4}{*}{ Sudeste } & Espírito Santo & 434 & 309 \\
\cline { 2 - 4 } & Minas Gerais & 244 & 175 \\
\cline { 2 - 4 } & Rio de Janeiro & 365 & 263 \\
\cline { 2 - 4 } & São Paulo & 550 & 373 \\
\hline \multirow{4}{*}{ Sul } & Paraná & 316 & 229 \\
\cline { 2 - 4 } & Santa Catarina & 471 & 341 \\
\cline { 2 - 4 } & Rio Grande do Sul & 740 & 548 \\
\hline
\end{tabular}

Tabela 1: Número de jovens investigados em cada estado do Sul e Sudeste

Inicia-se descrevendo o perfil destes sujeitos. Como já foi adiantado, todos os respondentes têm entre 18 e 24 anos, contudo, nas duas regiões, a idade mais proeminente é de 21 anos. A proporção entre homens e mulheres é idêntica, em ambas as regiões $66 \%$ dos informantes são garotas (em números absolutos: 741 no Sul e 750 no Sudeste).

Já em relação ao nível de instrução, apresenta-se o seguinte panorama:

SUL

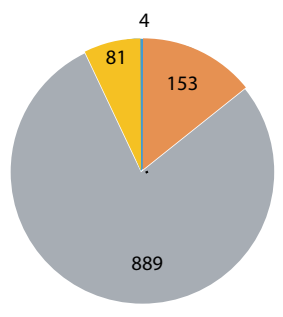

Ensino Fundamental

Ensino Médio

Graduação

- Pós-Graduação
SUDESTE

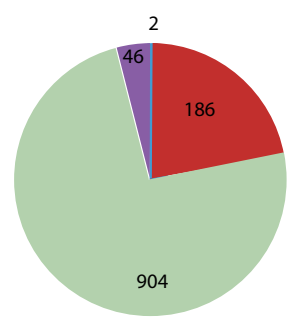

Ensino Fundamental

- Ensino Médio

Graduação

- Pós-Graduação

Gráfico 1: Escolaridade dos jovens investigados no Sul e Sudeste

Em termos percentuais, o índice de graduados é o mesmo: 80\% (889 jovens no Sul e 904 no Sudeste), portanto, a maioria nos dois casos. No investimento em pós-graduação, os sulistas alcançam quase o dobro: 7\% (81) em comparação aos $4 \%$ (46) do Sudeste.

Dentre graduandos e graduados, os cursos majoritariamente estão concentrados nas Ciências Sociais Aplicadas (592 jovens no Sul - 53\%, e 554 no Sudeste - 49\%), concentrados nos cursos de Comunicação. Sabe-se que, pelo fato de a Rede Brasil Conectado ser formada por pesquisadores dessa área, acabou criando um viés na pesquisa justamente pelo fato de o link do questionário ter circulado em maior medida nas redes desses professores. Ainda assim, há presença de jovens de outras áreas, sendo que as Engenharias estão em segundo lugar, com 7\% (77 jovens no Sul e 80 no Sudeste) nas duas regiões.

A maior distinção no perfil dos entrevistados vem do aspecto laboral: 63\% (707) dos jovens sulistas trabalham, em comparação aos $44 \%$ (498) que se declararam trabalhadores no Sudeste. Na questão da renda, em ambas as regiões, a maior concentração está entre $R \$ 2.655,00$ e $R \$ 5.241,00$, mas na região Sul há maior equilíbrio entre os de maior e menor renda familiar; já no Sudeste há leve tendência à concentração nas rendas mais altas. O que poderia explicar a distinção na situação laboral destes jovens, contudo, é apenas uma hipótese.

Sobre a situação de moradia, o quadro é aproximado: 55\% (614) dos sulistas moram com os pais em imóvel próprio, enquanto no Sudeste esse número é um pouco maior, 
${ }^{13}$ Os demais meios obtiveram os seguintes resultados, na ordem: revista on-line $(21 \%-237)$, TV $(16 \%-174)$, smartphone $(7 \%-76)$, jornal on-line $(7 \%-74)$, celular $(4 \%-50)$, livros $(2 \%-20)$ e internet $(1 \%-8)$. Contudo, $13 \%$ (144) admitem que precisam de todos os meios.

${ }^{14}$ Os demais meios obtiveram os seguintes resultados, na ordem: revista on-line $(18 \%-204)$, TV $(15 \%-162)$, smartphone $(6 \%-63)$, jornal on-line $(6 \% / 68)$, celular $(4 \%-40)$, livros $(2 \%-18)$ e internet $(1 \%-9)$. Contudo, $13 \%$ (146) admitem que precisam de todos os meios.

${ }^{15}$ Em função dos limites do artigo, serão apresentadas apenas tabelas completas da região Sul, os dados do Sudeste serão apenas descritos em comparação a essa região.
59\% (657). A segunda situação mais recorrente é a moradia com a família em imóvel alugado: $11 \%$ (124) no Sul e 13\% (149) no Sudeste. Essa condição de permanência na casa familiar é interessante, pois tem relação com a argumentação de Groppo (2015) que indica alargamento da condição juvenil no momento em que tradicionais marcadores que sinalizavam a entrada na vida adulta foram implodidos. Nesse caso, a saída da casa paterna/materna, ainda que seja realidade de um número reduzido dentro do grupo investigado, não está diretamente implicada na "perda" da condição juvenil desses sujeitos. A saída da casa dos pais implica, entre os jovens focalizados, a divisão de moradia com amigos em imóvel alugado. Nessas condições, encontramse no Sul $8 \%$ (97) dos jovens e, no Sudeste, 7\% (73). Na região Sul há, entre eles, leve tendência a morar sozinho em imóvel alugado, compreendendo $9 \%$ (99) dos entrevistados, já no Sudeste esta situação foi reportada por 6\% (66) dos jovens.

Quanto ao consumo midiático, tem-se a situação descrita a seguir nas questões que exploravam a importância dos meios no cotidiano. Ao serem questionados sobre quais meios não faziam falta no dia a dia, os jovens da região Sul apontaram em maior medida os seguintes: rádio ( $40 \%$ - 444 jovens), jornal impresso (39\% - 437 jovens), revista impressa (35\% - 387 jovens) e tablet $(34 \%-376$ jovens). ${ }^{13}$ No Sudeste os mesmos meios ocupam as quatro primeiras colocações, mas com posições distintas para o primeiro e o segundo lugar: jornal impresso (48\% - 538 jovens), seguido pelo rádio ( $43 \%$ - 480 jovens), revista impressa (36\% - 403 jovens) e tablet $\left(26 \%\right.$ - 293 jovens). ${ }^{14}$

Na sequência do questionário, uma pergunta aberta explorava os motivos pelos quais os meios indicados não faziam falta. Na região Sul o total de jovens que respondeu a essa questão é de 1.007, enquanto na região Sudeste o total é de 1.009 . Contudo, foi a partir das respostas dos jovens de todo o país que criaram-se categorias indutivas que evidenciavam os motivos pelos quais determinados meios não fazem falta: a) não possuo: em que o consumo do meio é condicionado ao acesso ou à posse; b) não uso/não gosto: o jovem possui ou teve acesso ao meio, mas prefere não utilizá-lo, caracterizando a falta de contato com o meio; c) foi substituído: o meio foi trocado por outro. Essa troca é motivada por alguma evolução: performance, custo, interatividade etc.; d) prefiro outro: os hábitos, as práticas e preferências dos jovens são determinantes para o consumo ou não do meio.

A partir do cruzamento dos meios indicados pelos jovens com as categorias indutivas anteriormente relatadas, elaborou-se a Tabela 2, a seguir, para a região $\mathrm{Sul},{ }^{15} \mathrm{em}$ que estão destacados em negrito os meios que foram mais proeminentes.

\begin{tabular}{|l|c|c|c|c|}
\hline & Prefiro outro & Não gosto/não uso & Não possuo & Foi substituído \\
\hline TV & $27,5 \%$ & $28,6 \%$ & $5,2 \%$ & $38,5 \%$ \\
\hline Tabler & $20,1 \%$ & $26,5 \%$ & $20,3 \%$ & $32,9 \%$ \\
\hline Smartphone & $12 \%$ & $35,7 \%$ & $29,3 \%$ & $22,8 \%$ \\
\hline Revista on-line & $33,3 \%$ & $25 \%$ & $14,1 \%$ & $27,8 \%$ \\
\hline Revista Imprensa & $23,3 \%$ & $26,7 \%$ & $9,7 \%$ & $40,1 \%$ \\
\hline Rádio & $21,2 \%$ & $34,3 \%$ & $10,9 \%$ & $33,4 \%$ \\
\hline $\begin{array}{l}\text { Nenhum, sinto que } \\
\text { preciso de todos }\end{array}$ & $0 \%$ & $0 \%$ & $0 \%$ & $0 \%$ \\
\hline Livros & $13,9 \%$ & $21,8 \%$ & $6,9 \%$ & $57,2 \%$ \\
\hline Jornal On-line & $38,15 \%$ & $29,4 \%$ & $11,51 \%$ & $20,93 \%$ \\
\hline Jornal Impresso & $23,31 \%$ & $22,32 \%$ & $10,6 \%$ & $43,77 \%$ \\
\hline Internet & $0 \%$ & $24 \%$ & $0 \%$ & $76 \%$ \\
\hline Celular & $24,56 \%$ & $30,02 \%$ & $8,75 \%$ & $36,66 \%$ \\
\hline
\end{tabular}

Tabela 2: Meios que não fazem falta e motivos indicados, região Sul

O meio mais dispensável para jovens da região Sul, como já ressaltado, foi o rádio, e, entre os principais motivos estão: "Não uso/não gosto" e "Foi substituído". 


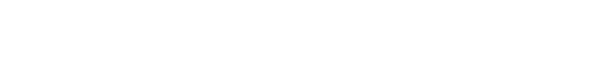

A justificativa "Foi substituído" se repete em jornal e revista como meios impressos. Além disso, o tablet também leva as duas justificativas. Já na região Sudeste, a categoria "Foi substituído" é mais relevante como justificativa para renúncia aos quatro meios mais apontados (os mesmos indicados por sulistas, como já mencionado). Há ainda que se destacar que o discurso dos entrevistados destoa nas respostas abertas, sendo que os sulistas apresentaram justificativas mais longas e elaboradas que jovens do Sudeste.

Para explorar o material qualitativo sem que fosse necessário analisar todas as respostas adquiridas, foram geradas nuvens de palavras que cruzavam as respostas abertas obtidas para determinado meio e em categoria específica. Por exemplo, a seguir apresenta-se a nuvem gerada com respostas dos jovens do Sul que indicaram não sentir falta do rádio dentro da categoria "Não uso/ não gosto".

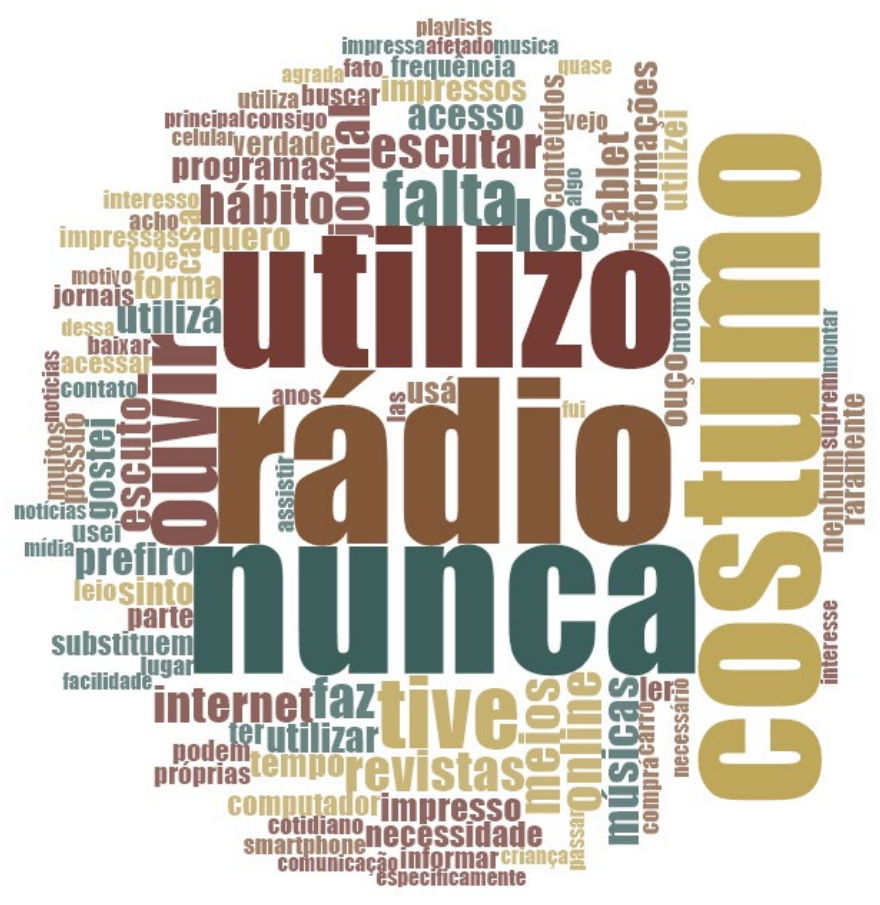

Figura 1: Nuvem de palavras sobre o meio, rádio, na categoria "Não uso/não gosto"

${ }^{16}$ Localizada no quadrante inferior esquerdo, na horizontal.

${ }^{17}$ No quadrante inferior direito, na vertical.

\footnotetext{
${ }^{18}$ As árvores foram geradas utilizando o termo de maior grandeza na nuvem.
}

De forma resumida, a grandeza das palavras mais proeminentes como "nunca", associadas a "costumo", "utilizo" e "ouvir" indicam que, no discurso dos jovens, o rádio aparece como desnecessário. A nuvem de palavras também permite inferir que a "internet" ${ }^{16}$ e as práticas "on-line" ${ }^{17}$ podem ser substitutos do rádio, embora tais palavras sejam menos presentes nas respostas, como indica a nuvem.

A leitura conjugada da categoria "Não uso/não gosto" na nuvem de palavras e na árvore de significados gerada a partir do termo rádio ${ }^{18}$ (a seguir), permite perceber o contexto discursivo em que se inserem algumas palavras da nuvem.

Com esse material, pode-se verificar o quanto o rádio é desnecessário, pois do lado esquerdo da árvore há a recorrência de expressões: "não tenho", "nunca fui adepta", "nunca senti necessidade", "nunca gostei", "nunca tive paciência para escutar", "eu não escuto músicas no rádio", entre outras. No lado direito é possível ter indicações das motivações para o baixo consumo do meio: "podem ser substituídas por outras", "faço minha própria playlist", "acesso pela internet", "prefiro minhas próprias MP3". Ou seja, a árvore de significados revela que o jovem prefere ter maior autonomia no seu consumo musical e que o alto índice de rejeição ao rádio, já que foi indicado como o meio que menos faz falta para os sulistas, pode estar relacionado à falta de "customização" do meio. 


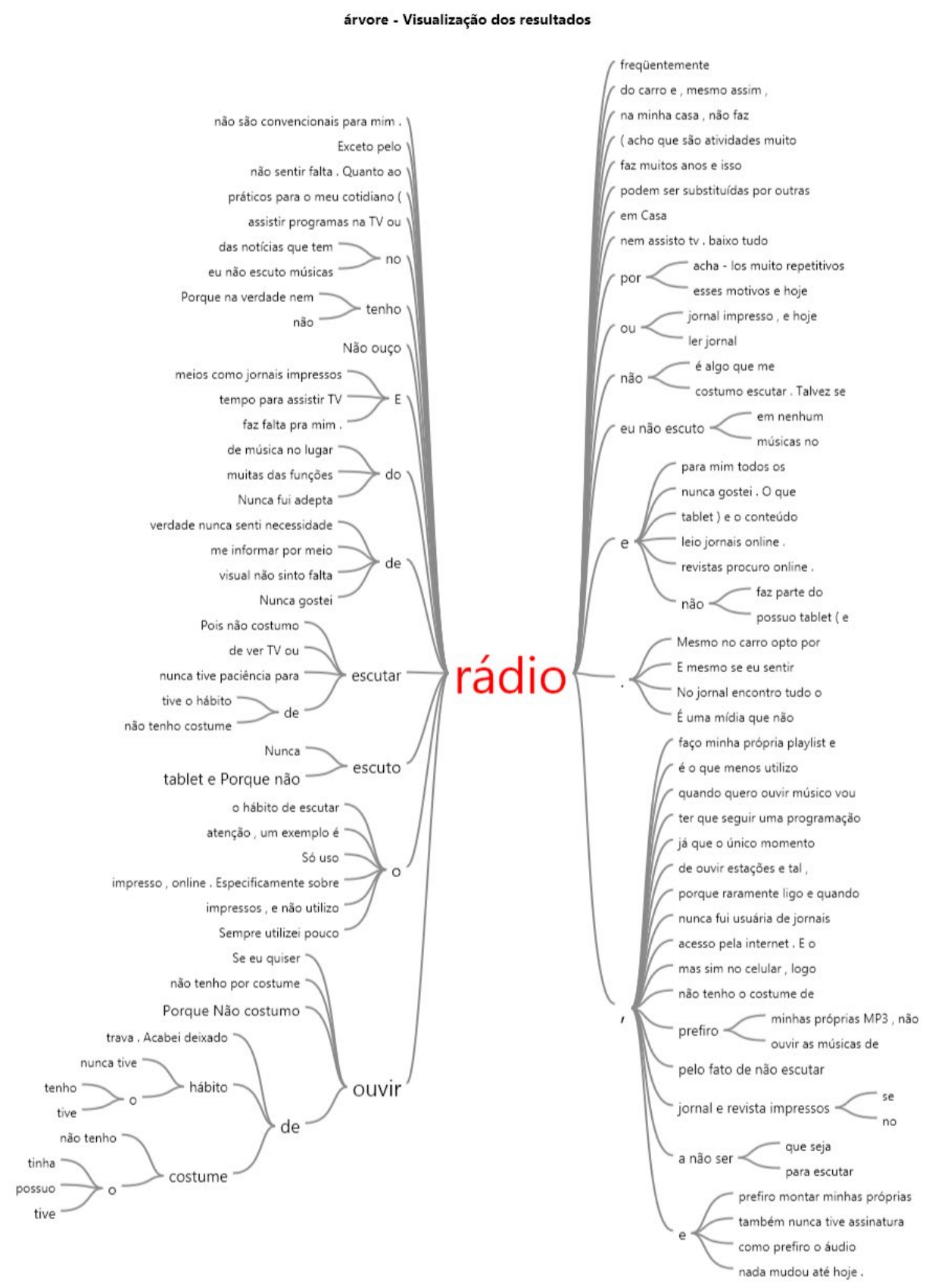

Figura 2: Árvore de significados - meio rádio - categoria "não uso/não gosto"

O rádio foi apontado pelos jovens do Sudeste como segundo meio mais dispensável. A categoria mais proeminente é "Foi substituído". A análise da nuvem de palavras indicou que o consumo não é muito presente no cotidiano juvenil. A grandeza de palavras como: "substituídos", "obsoletos" e "desnecessários" corroboram a hipótese. Além disso, assim como no Sul, as palavras mais proeminentes da nuvem, "internet" e "on-line", permitem inferir que esses recursos podem ser substitutos ao rádio. Na árvore de significados, cujo o termo central é "internet", há expressões que refirmam as hipóteses de que outros meios o substituíram.

O segundo meio que menos faz falta aos jovens da região Sul é o "jornal impresso". O mesmo recebeu o primeiro lugar entre jovens da região Sudeste. Assim como o registrado no rádio, a justificativa "Foi substituído" aparece para ambas as regiões. No caso de jovens sulistas, é possível perceber, com a proeminência de termos como "on-line", "jornal", "substituídos", "digitais" e "portais", que eles possivelmente substituíram o jornal impresso pelo equivalente on-line. Na árvore de significados, que tem como centro a palavra "internet", percebe-se que custo, atualização e velocidade são motivos para a troca. 
${ }^{19}$ Interessante demarcar que esta questão era posterior à anteriormente apresentada na ordem de aplicação do questionário e percebe-se que parte dos jovens já havia abandonado o questionário neste ponto.
Já no caso da região Sudeste, o "jornal impresso" foi apontado pelos jovens como sendo o que menos faz falta. Assim como na região Sul, os termos "online", "jornal" e "impresso", "substitui", "digitais" e "conteúdo", denotam essa mudança. A árvore de significados apresenta justificativas semelhantes às usadas pelos sulistas, com o adendo da "diversidade/facilidade" do meio como umas das justificativas. Além disso, outra diferença nas respostas das duas regiões foi que, no caso do Sul, os jovens evidenciaram outra dimensão não exposta pelos jovens do Sudeste, sobretudo, nas expressões que apontam para a consciência que os entrevistados têm das mudanças decorrentes do acesso digital: "os dispositivos móveis substituem", "parece conseguir substituir a experiência". E indicam vantagens dessas mudanças: "de forma muito mais fácil", "já supre eles pra mim", "o acesso é mais fácil" e "a internet consigo acessar".

O segundo bloco de questões que será aqui tratado explorava a atenção dedicada aos meios, no intuito de compreender usos convergentes ou, ainda, habilidades multitarefas dos jovens. A partir das respostas dos entrevistados de todo o país foram criadas categorias indutivas que evidenciam os motivos pelos quais determinado meio merece atenção exclusiva: a) conteúdo: quando o tipo de conteúdo requer maior atenção; b) contingência: quando as circunstâncias de uso/acesso são determinantes; c) interlocução: quando a necessidade ou desejo de comunicação interpessoal demandam maior atenção; d) perfil: devido a preferências, gostos ou mesmo hábitos individuais; e) performance do meio: as características do meio determinam o grau de atenção; e f) tipo de tarefa: devido à complexidade da mesma.

O número de entrevistas, bem como o de respostas das duas regiões se assemelha: dos sulistas, 923 responderam à questão e, do Sudeste, $940 .{ }^{19}$ No Sul, os quatro meios aos quais os jovens dedicam atenção exclusiva são: livro ( $73 \%-676$ jovens), jornal impresso ( $29 \%-271$ jovens), revista impressa ( $26 \%$ - 240 jovens) e computador ( $24 \%$ - 219 jovens). Na região Sudeste os meios citados foram os mesmos, mas há pequena diferença em relação à posição do computador, que aparece em segundo lugar, com 24\% (230). Em primeiro lugar também está o livro (69\% - 648 jovens), em terceiro, a revista impressa ( $23 \%$ 219 jovens) e, na sequência, o jornal impresso ( $20 \%-189$ jovens).

O principal meio escolhido pelos jovens das regiões Sul e Sudeste como aquele que merece atenção exclusiva foi o livro. Os fatores verificados para essa escolha foram guiados pelas categorias indutivas construídas na análise de respostas abertas que exploravam os motivos da atenção exclusiva. No caso do Sul, as duas categorias mais proeminentes são "perfil" e "performance do meio". Já no Sudeste, as características do "perfil" do usuário foram mais determinantes.

As respostas abertas dessa última categoria assemelham-se nas duas regiões. Em ambas é possível perceber, com base na leitura das nuvens de palavras, a proeminência dos termos "atenção" e "concentração". Na região Sul, sobretudo, é evidenciado o reforço sobre o quanto o livro demanda concentração em função de características pessoais dos jovens investigados, com base nas expressões da árvore de significados, construída a partir do termo "concentração", que revelam certo esforço para a manutenção desta, com expressões como "para manter", "para melhorar", "para conseguir", "para não perder", "preciso de", "para ter 100\% de", entre outras. Como já mencionado, na região Sudeste o perfil do jovem também é determinante nos tipos de uso/consumo de meios operados. Contudo, as expressões principais que giram em torno do termo "concentração" são distintas: "não consigo fazer isso paralelamente", "não consigo me concentrar em", demonstrando ainda que, com discurso um pouco distinto, as razões se assemelham.

Na exploração das respostas abertas da categoria indutiva "performance do meio", proeminente nas respostas do Sul, os termos "atenção" e "concentração" também aparecem bem destacadas na nuvem de palavras. Porém, para entendimento 
${ }^{19}$ Para este artigo, foram escolhidos os dois primeiros meios mais citados de cada região, por apresentarem respostas distintas que enriquecem o comparativo.

\footnotetext{
${ }^{20}$ Há que se destacar, contudo, que os jovens da região Sudeste foram mais sucintos em suas respostas, o que restringiu maiores interpretações. Também foram identificadas algumas nuances que os singularizam, como o fato de o rádio ser o meio de menor consumo entre os sulistas, enquanto os jovens do Sudeste apontam que o jornal impresso é o meio de menor participação em seu cotidiano.
}

além dessas expressões, procurou-se olhar para outras de menor proeminência, que contribuíssem para demais explorações. Termos como "exigem", "requer", "precisa" e "necessitam" indicam demanda do meio por atenção e concentração. Ou seja, alguns jovens atribuem a concentração que dedicam a um ou outro meio ao seu perfil de uso, como já mencionado, outros depositam tais exigência nas performances do meio. E, por alguns momentos, evidencia-se que as duas categorias aparecem imbricadas no discurso juvenil.

Em função do grande destaque das palavras "atenção" e "concentração" que se repetiram como principais em todas as nuvens geradas na pergunta sobre dedicação exclusiva, optou-se por suprimir respostas que continham estes termos a fim de explorar novas justificativas à atenção dedicada. Assim, foram geradas novas nuvens de palavras e árvores de significado com número menor de respostas. Essas, por sua vez, no caso do Sul, demonstraram grande destaque aos termos "livro", "revista" e "texto", o que pode ser indicativo de que meios impressos e/ou a linguagem verbal demandam maior concentração no entendimento dos jovens.

O segundo meio mais citado pelos sulistas foi o "jornal impresso", ${ }^{19}$ meio citado em quarto lugar pelos jovens da região Sudeste. Assim como no caso do livro, as categorias "perfil" e "performance do meio" foram mais registradas no Sul. Entre os entrevistados do Sudeste as mesmas categorias foram assinaladas. No caso do Sul, na categoria "perfil", suprimindo-se "atenção" e "concentração" da nuvem, verifica-se pluralidade de termos em que "consigo" sobressai, ratificando a descrição da categoria "perfil" que está relacionada a gostos e hábitos individuais. No caso do Sudeste, isso também se verifica.

\section{Considerações finais}

Acerca dos resultados, o perfil dos jovens investigados é bastante similar nas duas regiões: maioria formada por mulheres, com renda familiar aproximada, graduados e que residem com os pais em casa própria. Destoam apenas no aspecto laboral, em que os sulistas estão mais inseridos no mundo do trabalho, e no investimento em pós-graduação, quesito em que os jovens do Sul também estão à frente. Torna-se evidente que essas características de perfil indicam que o grupo pesquisado não abarca todos os estratos sociais. Contudo, esse viés pode ser explicado pela forma como o link do questionário circulou nacionalmente, uma vez que a principal estratégia utilizada foi a divulgação via redes sociais dos pesquisadores das 27 equipes que compõem a Rede Brasil Conectado.

Ainda que se tenha discutido sobre a pluralidade que constitui e ajuda a construir a juventude contemporânea (GROPPO, 2000; MARGULIS; URRESTI, 2008) o que se percebeu aqui, em última instância, foi aproximação entre as práticas de consumo midiático dos jovens das duas regiões economicamente mais desenvolvidas do país. ${ }^{20}$ Os meios impressos, por exemplo, recebem mais atenção exclusiva dos dois grupos, mas entre sulistas essa dedicação é um pouco mais acentuada, em razão do perfil dos respondentes. Ao mesmo tempo, os dois grupos revelaram que os impressos, no geral, com exceção do livro, são os meios que menos sentem falta no cotidiano. Ou seja, curiosamente, alguns dos meios que os jovens indicam necessitar de maior atenção no consumo estão entre os que menos sentem falta. O que pode sugerir menor predisposição ou interesse em meios que exijam mais concentração ou que quebrem a lógica do uso simultâneo, já que grande maioria demonstra estar inserida na cultura da convergência (JENKINS, 2008), seja no tipo de consumo que associa mais de um meio ou na migração dos meios tradicionais para os digitais.

Assim, ambososgruposse mostraramafeitosa usos concomitantes, multiconectados e multifuncionais. Contudo, essa inserção dentro do contexto cultural, tecnológico e midiático da convergência pode ser explicado pelo maior acesso aos meios, especialmente os digitais, em função da condição econômica familiar, mas também pela qualidade do tráfego da internet nas duas regiões em questão. 
Aponta-se ainda que o perfil dos jovens é bastante determinante da forma como se relacionam com os meios, seja com atenção exclusiva ou não, muito mais do que a tarefa que executa ou o meio que utiliza. O que indica a importância da subjetividade e competência cultural nos processos de consumo cultural e midiático (MARTíN-BARBERO, 2003).

Por fim, o emprego dos softwares, especialmente o Nvivo, possibilitou análise das questões abertas sem que fosse necessário ler a totalidade das respostas que ultrapassa a marca de 9 mil jovens. Essa exploração foi inovadora para o grupo de investigadores e a experiência foi bastante positiva, ainda que alguns limites possam ser apontados, como o fato de algumas respostas figurarem em mais de uma categoria a partir da codificação automática realizada. Fato que tentou ser contornado gerando-se nuvens de palavras e árvores de significado que destacassem respostas mais singulares, como foi apontado na análise dos dados.

\section{Referências}

BOURDIEU, P. Sociología y cultura. Ciudad de México, DF: Grijalbo, 1990.

CRESSWELL, J. W. Projeto de pesquisa: métodos qualitativo, quantitativo e misto. Tradução Luciana de Oliveira da Rocha. 2. ed. Porto Alegre: Artmed, 2007.

ESTATUTO da Juventude. Portal da Juventude, Brasília, DF, 21 nov. 2014. Disponível em: <http://bit.ly/2kT6ggH>. Acesso em: 16 out. 2017.

FEIXA, C. De jóvenes, bandas y tribus: antropología de la juventud. 2. ed. Barcelona: Ariel, 1999.

. A construção histórica da juventude. In: CACCIA-BAVA, A.; FEIXA, C.; GONZALES CANGAS, Y. (Org.). Jovens na América Latina. São Paulo: Escrituras, 2004. p. 251-327.

GARCÍA CANCLINI, N. El consumo cultural: una propuesta teórica. In: SUNKEL, G. El consumo cultural en América Latina: construcción teórica y líneas de investigación. 2. ed. Bogotá: Convenio Andrés Belo, 2006. p. 72-95.

GARCÍA CANCLINI, N.; ROSAS MANTECON, A. Políticas culturales y consumo cultural urbano. In: GARCÍA CANCLINI, N. (Coord.). La antropología urbana en México. México: FCE; Conaculta; UAM, 2005. p. 168-195.

GROPPO, L. A. Juventude: ensaios sobre sociologia e história das juventudes modernas. Rio de Janeiro: Difel, 2000.

- Teorias pós-críticas da juventude: juvenilização, tribalismo e socialização ativa. Revista Latinoamericana de Ciencias Sociales, Niñez y Juventud, Manizales, v. 13, n. 2, p. 567-579, ago. 2015.

JENKINS, H. Cultura da convergência. Tradução Susana Alexandria. São Paulo: Aleph, 2008.

MARGULIS, M.; URRESTI, M. La juventud es más que una palabra. In: MARGULIS, M. (Ed.). La juventud es más que una palabra: ensayos sobre cultura y juventud. Buenos Aires: Biblos, 2008. p. 13-30.

MARTÍN-BARBERO, J. Dos meios às mediações: comunicação, cultura e hegemonia. Tradução Ronaldo Polito e Sergio Alcides. 2. ed. Rio de Janeiro: UFRJ, 2003.

OROZCO GÓMEZ, G.; GONZÁLEZ, R.. Ciudad de México, DF: Tintable, 2012. 
SCHMITZ, D. M. Consumo, sentidos, usos e apropriações nas pesquisas de recepção: nem tão sinônimos, nem tão distantes. InTexto, Porto Alegre, n. 34, p. 255-275, set./dez. 2015.

TEIXEIRA, A. N.; BECKER, F. Novas possibilidades da pesquisa qualitativa via sistemas CAQDAS. Sociologias, Porto Alegre, v. 3, n. 5, p. 94-113, jan./jun. 2001.

TOALDO, M.; JACKS, N. Consumo midiático: uma especificidade do consumo cultural, uma antessala para os estudos de recepção. In: ENCONTRO ANUAL DA ASSOCIAÇÃO NACIONAL DOS PROGRAMAS DE PÓS-GRADUAÇÃO EM COMUNICAÇÃO, 22., 2013, Salvador. Anais... Salvador: Compós, 2013. p. 1-9. 